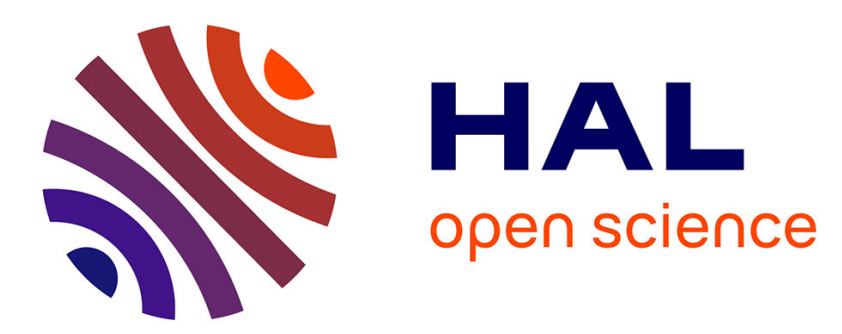

\title{
Assessing spatiotemporal associations in the occurrence of badger-human conflict in England
}

John Davison, Timothy J. Roper, Charles J. Wilson, Matthew J. Heydon, Richard J. Delahay

\section{- To cite this version:}

John Davison, Timothy J. Roper, Charles J. Wilson, Matthew J. Heydon, Richard J. Delahay. Assessing spatiotemporal associations in the occurrence of badger-human conflict in England. European Journal of Wildlife Research, 2010, 57 (1), pp.67-76. 10.1007/s10344-010-0400-2 . hal-00668052

\section{HAL Id: hal-00668052 https://hal.science/hal-00668052}

Submitted on 9 Feb 2012

HAL is a multi-disciplinary open access archive for the deposit and dissemination of scientific research documents, whether they are published or not. The documents may come from teaching and research institutions in France or abroad, or from public or private research centers.
L'archive ouverte pluridisciplinaire $\mathbf{H A L}$, est destinée au dépôt et à la diffusion de documents scientifiques de niveau recherche, publiés ou non, émanant des établissements d'enseignement et de recherche français ou étrangers, des laboratoires publics ou privés. 


\title{
Assessing spatiotemporal associations in the occurrence of badger-human conflict in England
}

\author{
John Davison - Timothy J. Roper • Charles J. Wilson • \\ Matthew J. Heydon • Richard J. Delahay
}

Received: 24 December 2009/Revised: 3 May 2010 / Accepted: 7 May 2010 /Published online: 8 June 2010

(C) Her Majesty the Queen in Right of UK 2010

\begin{abstract}
Examples from a variety of taxa demonstrate that under certain circumstances, the exclusion or translocation of 'problem' animals is ineffective in resolving humanwildlife conflicts and may even elicit new problems elsewhere. Damage caused by badger setts (burrows) is an important source of human-wildlife conflict in the UK and is commonly managed by excluding badgers from all or part of problem setts. We used records of licences issued for the management of such problems and a novel statistical approach to assess spatiotemporal associations between
\end{abstract}

Communicated by C. Gortázar

Electronic supplementary material The online version of this article (doi:10.1007/s10344-010-0400-2) contains supplementary material, which is available to authorized users.

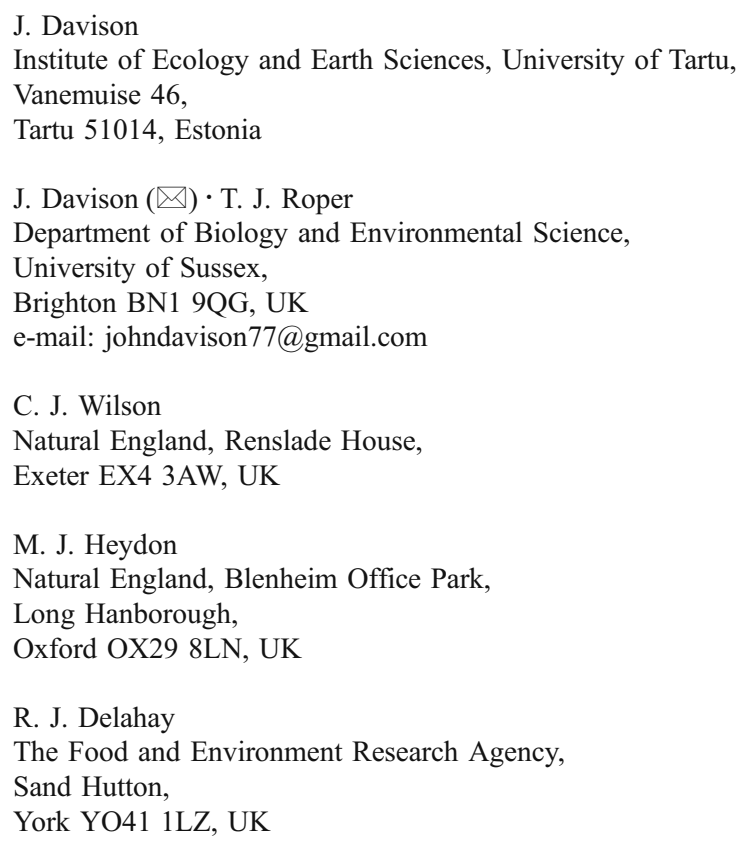

York YO41 1LZ, UK

problem cases in England from 2002 to 2005 . We predicted that management at urban badgers' setts, and particularly exclusion of badgers from urban main setts, would give rise to subsequent problems at focal setts and in neighbouring areas. Frequencies of problems occurring at individual setts were similar in urban and rural areas. In areas neighbouring setts subjected to management action, the background frequency of problems was higher in urban than in rural areas, reflecting the occurrence of problems at a higher proportion of urban setts. The frequency of new cases arising at or in the vicinity of managed setts within a critical time period after management action was not significantly different from the background frequency of problems for any combination of land use, sett type and management approach. This finding suggests that the measures currently employed for managing problem setts do not importantly increase the likelihood of problems reoccurring in the same location or emerging nearby.

Keywords Badger exclusion · Land use - Management action · Sett · Urban mammals · Wildlife damage

\section{Introduction}

One of the central aims of wildlife management is to successfully resolve instances of human-wildlife conflict (Conover 2002; Adams et al. 2005). However, this raises a question as to what constitutes 'successful resolution'. In some cases, it may be sufficient to evaluate a management approach simply in terms of its ability to resolve individual problems in the short term. However, a more meaningful assessment should also take account of potentially undesirable side effects. This can be extremely challenging because the complexity of underlying ecological relation- 
ships can make the outcome of management interventions difficult to predict. A salient example is provided by a recent large-scale field experiment which revealed that attempts to control the transmission of bovine tuberculosis to cattle by means of culling badgers (Meles meles) led, in some circumstances, to an increase in the incidence of the disease in both cattle and badgers (Donnelly et al. 2006; Woodroffe et al. 2006).

In the present study, we evaluated the potential consequences of interventions to manage a different type of badger-human conflict: damage caused by badger setts (burrows). Such problems can occur when badgers excavate setts close to man-made structures (e.g. houses, roads) or on agricultural land (e.g. crops, forestry; Harris et al. 1994; Wilson and Symes 1997; Matthews and Wilson 2005; Delahay et al. 2009). Specifically, we asked whether the destruction of problem setts, or other types of management action, results in the reoccurrence of comparable sett-related problems, either at the same location or nearby.

In the UK, badgers and their setts are protected by law (the Protection of Badgers Act 1992), and the management of related problems is regulated by a system of licensing. Analysis of historical records shows that the number of licenses issued in England increased in recent years, particularly in urban areas (Delahay et al. 2009). Options for the management of problem setts are relatively limited, with the most common approach involving the installation of one-way gates over entrance holes to exclude badgers from all or part of a sett, followed by destruction of the empty structure ('sett closure'). Less frequently, other techniques are employed, including the use of chemical repellents (prior to the withdrawal of legal authorisation for the only available product), repairing the damage caused by setts, altering the location of entrance holes, or rarely, direct action against badgers, such as translocation (see Wilson and Symes (1997) and Matthews and Wilson (2005) for details). The target of management action may be either a 'main' sett, which is a relatively large burrow system constituting the principal residence and breeding site for a badger social group and can be continuously occupied by badgers for a period of several decades, or an 'outlier', which is smaller and usually intermittently used by fewer individuals (Kruuk 1978; Thornton 1988).

In principle, complete closure of a sett should eliminate the possibility of problems reoccurring at the same location, since the original sett should no longer exist. In practice, however, the problem may reoccur at some subsequent time if, for example, sett closure is unsuccessful or the excluded badgers later return to the same site and re-excavate the closed sett. Also, radio-tracking data show that once badgers are excluded from a problem sett, they may dig or enlarge another sett at some other location within their original home range (Defra 2007), meaning that a further problem could potentially arise there. In short, management actions that appear to be successful in the short term could be ineffective in the long term because they fail to prevent the reoccurrence of a problem, either at the same location or nearby. Henceforth, we use the term 'reoccurrences' to refer to problems arising at the sett where a management action was undertaken and 'neighbouring cases' to refer to problems arising at a nearby location. We also use the terms 'focal sett' and 'focal case', respectively, to describe the specific sett and management action in relation to which reoccurrences and neighbouring cases are measured.

Very few large-scale investigations into spatiotemporal association between wildlife management interventions have been undertaken, presumably due to the lack of records and the financial and logistical constraints of undertaking large field trials. In the present study, we used a dataset of historical licensing records to determine the extent to which management actions, intended to mitigate sett-related problems, resulted in reoccurrences or neighbouring cases. The practical implications are that if the rate of reoccurrences or neighbouring cases is high, then the value of the relevant management actions is reduced, and new approaches may need to be developed. We carried out analyses separately for urban and rural areas, since the frequency of problems related to badger setts is greater and has recently increased, in the former (Delahay et al. 2009). Furthermore, previous studies have revealed differences between urban and rural habitats in the types of sett-related problems that arise (Delahay et al. 2009) and in the patterns of sett use exhibited by badgers (Davison et al. 2008).

We attempted to answer the following specific questions: (a) Does the higher frequency of problems recorded in urban compared with rural areas represent multiple reoccurrences at individual setts or low numbers of problems occurring at many different setts? (b) Subsequent to licensed action, does the frequency of 'reoccurrences' or of 'neighbouring cases' differ from the background frequency of problems? (c) Does the frequency of 'reoccurrences' or of 'neighbouring cases' vary in relation to land use, the type of management intervention or the type of sett involved? Individual case studies and anecdotal reports suggest that intractable problems are more likely to occur in urban compared with rural areas (e.g. Defra 2005). Therefore, we predicted that reoccurrences of problems should be more frequent in the former habitat. Given the importance to badgers of main setts and the limited availability in urban areas of unproblematic sett locations, we also predicted that greater than usual frequencies of both reoccurrences and neighbouring cases should be particularly associated with closure of main setts and management in urban areas. 


\section{Methods}

\section{The licensing process}

Applications for licences to interfere with badgers or their setts for the purpose of damage prevention were assessed during site visits by Wildlife Advisers from the licensing authority (the Department for Environment Food and Rural Affairs, Defra). Licences were subsequently granted if the advisers considered (a) that there was evidence of, or the potential for, a serious problem, (b) that there were no other practicable methods of solving the problem, and (c) that licensed action was likely to be successful. If any of these criteria were not met, then a licence was not issued.

\section{Data sources}

Data were extracted from a Defra database (the Wildlife Intranet Linked Database) containing records of all licence applications for England from January 2002 to March 2005. For every licence application (i.e. each 'case'), details were available describing the nature of the problem and the conditions associated with any licence that was granted. For the purposes of our analyses, only applications that resulted in the issuing of a licence to carry out action at a problem sett were considered, and cases that were not licensed or that were unconnected to setts were omitted. Although the granting of a licence did not necessarily result in any management action being taken, previous analysis of a subsample of cases that were monitored showed that action took place in $78 \%$ and $87 \%$ of rural and urban cases, respectively (Delahay et al. 2009). Moreover, as monitoring sometimes occurred before the expiry of a licence, action may still have taken place in a considerable proportion (55\%) of cases where no management action was recorded (R Delahay \& J Davison, unpublished data).

For each case, the following information was extracted from the database: the geographical location of the problem (an eight-figure grid reference accurate to $100 \mathrm{~m}$ and a site address), the date of the licence application, the date by which the work was to be completed (i.e. the expiry date of the licence in days after the application date), the type of sett causing the problem (i.e. main sett or outlier), and the result of action to be carried out under licence (i.e. total sett closure or other action). 'Other action' commonly referred to partial sett closure but also included other interventions such as repairing damage caused by a sett or altering the location of a sett entrance. All cases were classified as 'urban' or 'rural' on the basis of urban area boundaries resulting from the 2001 UK national census (see Delahay et al. (2009) for definitions).
Spatiotemporal association

While certain established point pattern analysis techniques could reveal the existence of geographical clusters of cases with similar licence application dates (e.g. Knox test: Knox 1964) or clusters of new cases within a certain time period following licence applications (e.g. space-time K-function: Diggle et al. 1995), they could not be used to assess the frequency of new cases occurring within a given time period after licensed action was completed. This is important because the time period between an application and the expiry of the associated licence (i.e. the date by which management action should have been completed) varied on a case-by-case basis in our dataset. Moreover, established techniques would not permit a simple assessment of the frequency of new cases in relation to environmental variables and case-specific characteristics, such as land use, sett type and management action. Therefore, following the recommendations of Fortin et al. (2002) and Fortin and Dale (2005), we developed a novel statistic and randomisation procedure in order to carry out the requisite analyses.

Our statistic, the observed $K$ statistic (Ko), represented the mean frequency, across all cases in the dataset, of other cases arising within a given distance and time since the expiry of the licence for focal cases, such that

$\widehat{K}(s u)=\frac{1}{n}\left(\sum_{\substack{i=1 \\ i \neq j}}^{n} \sum_{\substack{j=1 \\ j \neq i}}^{n} I_{s}(i, j) I_{u}(i, j)\right)$

where $s$ and $u$, respectively, are spatial (distance in meters) and temporal (days) scales for analysis; $I_{s}(i, j)$ is an indicator function with the value 1 if $d_{i j} \leq s$ or 0 otherwise, where $d_{i j}$ is the distance (meter) between cases $i$ and $j ; I_{u}(i, j)$ is an indicator function with the value 1 if $0 \leq t_{i j} \geq u$ or 0 otherwise, where $t_{i j}$ is the time difference (days) between the expiry date of licence $i$ and the application date of case $j$; and $n$ is the total number of cases in the dataset. Correction for edge effects is an important consideration when analysing point patterns within spatial or temporal limits (e.g. Diggle 1983; Haase 1995). In this dataset, the temporal scale of interest $(u)$ extended beyond the limit of the study period for some cases, while for a small number of cases, the spatial scale of interest $(s)$ extended beyond the edges of the study area that were bordered by land (while other cases were located close to the coastal boundaries of the study area, the areas adjacent to these (i.e. the sea) could be assumed with certainty to contain no other cases). To correct for edge effects, we used the buffer zone approach, which is slightly inefficient, since informa- 
tion from some edge data points is lost but is otherwise an unbiased method (Haase 1995). We considered the sample sizes in our analyses (Tables 1 and 2) to be sufficiently large for the loss of a small number of edge data points to be acceptable. Thus, only points for which $u$ was contained within the study period and $s$ within the study area were considered points $i$; points $j$ additionally included points where $u$ exceeded the limit of the study period and $s$ exceeded the land boundary of the study area.

An approximate randomisation procedure was used to create a distribution of expected $K$ statistics $(\mathrm{Ke})$, which represented the mean frequency of cases arising within a critical distance of focal cases during a randomly chosen 1year period within the study period (i.e. potentially before, after or coinciding with licensed action at focal setts). This served the dual purposes of providing a comparison of the background frequency of problem cases occurring under different conditions (i.e. in relation to land use and sett type) and providing a baseline against which to measure the frequency of cases occurring in the time period of interest (i.e. the period after licensed action had taken place, as described by Ko). Thus, if Ko was more extreme than a particular quantile (e.g. 95\%) within the distribution of randomised $\mathrm{Ke}$ statistics, this was taken to represent significant spatiotemporal association between problem cases. Each Ke statistic was calculated by randomly permuting the application dates associated with all cases. Buffer zone edge effect corrections were applied to every permuted dataset as described above. A Ke statistic (as in Eq. 1) was calculated for each of 999 permuted datasets, and the 50th percentile of the resulting vector of ranked Ke statistics was taken as a measure of central tendency (median) within the distribution of Ke values.

Since we wanted to investigate processes occurring in different environments, observed and median expected $K$ statistics were calculated separately for urban and rural cases. Within each land use category, $K$ statistics were also calculated for subsets of data representing all combinations of different sett types and management actions. For analysis of subsets of data, all cases, regardless of their characteristics, were considered as points $j$ (see Eq. 1).

Using this method, we calculated separate $K$ statistics for applications reoccurring at the same sett ('reoccurrences') and those cases occurring in an area close to the original sett ('neighbouring cases'; i.e. from $1 \mathrm{~m}$ up to the scale of interest: see below). Thus, Ko for reoccurrences corresponded approximately to the proportion of setts experiencing a new problem within the critical temporal scale; and Ko for neighbouring cases represented the mean number of other cases arising within the critical spatial

Table 1 The frequency of reoccurrence of applications for licences to interfere with badger setts in the 1-year period following licensed management action, relative to land use (urban or rural), sett type (main or outlier) and management approach (total sett closure or other)

\begin{tabular}{|c|c|c|c|c|c|c|c|c|c|}
\hline Habitat & Sett type & Management & $N$ setts & $N$ problems & Ko & Median Ke & Ke lower & Ke upper & $P$ \\
\hline \multirow[t]{9}{*}{ Urban } & All & All & 249 & 21 & $0.084(+20.0)$ & 0.07 & $0.044(-37.1 \%)$ & $0.097(+38.6 \%)$ & 0.77 \\
\hline & Main & All & 105 & 9 & $0.086(+7.5)$ & 0.08 & $0.036(-55 \%)$ & $0.122(+52.5 \%)$ & 0.26 \\
\hline & Outlier & All & 144 & 12 & $0.083(+33.9)$ & 0.062 & $0.031(-50 \%)$ & $0.097(+56.5 \%)$ & 0.45 \\
\hline & All & Total & 150 & 10 & $0.067(+24.1)$ & 0.054 & $0.023(-57.4 \%)$ & $0.088(+63 \%)$ & 0.45 \\
\hline & All & Other & 99 & 11 & $0.111(+23.3)$ & 0.09 & $0.042(-53.3 \%)$ & $0.144(+60 \%)$ & 0.25 \\
\hline & Main & Total & 44 & 3 & $0.068(+19.3)$ & 0.057 & $0(-100 \%)$ & $0.135(+136.8 \%)$ & 0.86 \\
\hline & Main & Other & 61 & 6 & $0.098(+11.4)$ & 0.088 & $0.032(-63.6 \%)$ & $0.15(+70.5 \%)$ & 0.76 \\
\hline & Outlier & Total & 106 & 7 & $0.066(+29.4)$ & 0.051 & $0.019(-62.7 \%)$ & $0.089(+74.5 \%)$ & 0.38 \\
\hline & Outlier & Other & 38 & 5 & $0.132(+41.9)$ & 0.093 & $0.023(-75.3 \%)$ & $0.179(+92.5 \%)$ & 0.42 \\
\hline \multirow[t]{9}{*}{ Rural } & All & All & 489 & 25 & $0.051(-5.6)$ & 0.054 & $0.037(-31.5 \%)$ & $0.071(+31.5 \%)$ & 0.31 \\
\hline & Main & All & 220 & 9 & $0.041(-25.5)$ & 0.055 & $0.029(-47.3 \%)$ & $0.081(+47.3 \%)$ & 0.64 \\
\hline & Outlier & All & 269 & 16 & $0.059(+9.3)$ & 0.054 & $0.032(-40.7 \%)$ & $0.077(+42.6 \%)$ & 0.66 \\
\hline & All & Total & 204 & 12 & $0.059(+13.5)$ & 0.052 & $0.022(-57.7 \%)$ & $0.081(+55.8 \%)$ & 0.45 \\
\hline & All & Other & 285 & 13 & $0.046(-14.8)$ & 0.054 & $0.031(-42.6 \%)$ & $0.08(+48.1 \%)$ & 0.73 \\
\hline & Main & Total & 58 & 3 & $0.052(-13.3)$ & 0.06 & $0(-100 \%)$ & $0.128(+113.3 \%)$ & 0.71 \\
\hline & Main & Other & 162 & 6 & $0.037(-30.2)$ & 0.053 & $0.025(-52.9 \%)$ & $0.085(+60.4 \%)$ & 0.29 \\
\hline & Outlier & Total & 146 & 9 & $0.062(+26.6)$ & 0.049 & $0.021(-57.1 \%)$ & $0.085(+73.5 \%)$ & 0.47 \\
\hline & Outlier & Other & 123 & 7 & $0.057(-1.7)$ & 0.058 & $0.025(-56.9 \%)$ & $0.096(+65.5 \%)$ & 0.92 \\
\hline
\end{tabular}

$N$ setts is the total number of setts where problems occurred; $N$ problems is the total number of new problems that reoccurred in the period following management action; Ko and Ke are the observed and expected frequencies of new problems, respectively (see "Methods" section for calculation); and two-tailed $95 \%$ confidence limits around median Ke are presented. The percentage deviations from the median Ke are presented in parentheses for the respective values of Ko and the lower and upper confidence limits. $P$ is the approximate two-tailed $P$ value for differences between Ko and median Ke 
Table 2 The frequency of applications for licences to interfere with badger setts occurring in areas neighbouring $(<800 \mathrm{~m})$ focal setts in the 1 -year period following management action, relative to land use (urban or rural), sett type (main or outlier) and management approach (total sett closure or other)

\begin{tabular}{|c|c|c|c|c|c|c|c|c|}
\hline Habitat & Sett type & Management & $N$ setts & $N$ problems & Ko & Median Ke & Ke upper & $P$ \\
\hline \multirow[t]{9}{*}{ Urban } & All & All & 249 & 143 & $0.574(+5.9 \%)$ & 0.542 & $0.611(+12.73 \%)$ & 0.25 \\
\hline & Main & All & 105 & 60 & $0.571(+7.48 \%)$ & 0.531 & $0.644(+21.22 \%)$ & 0.30 \\
\hline & Outlier & All & 144 & 83 & $0.576(+2.58 \%)$ & 0.562 & $0.660(+17.53 \%)$ & 0.37 \\
\hline & All & Total & 150 & 78 & $0.520(+3.17 \%)$ & 0.504 & $0.606(+20.24 \%)$ & 0.39 \\
\hline & All & Other & 99 & 65 & $0.657(+10.24 \%)$ & 0.596 & $0.727(+21.99 \%)$ & 0.23 \\
\hline & Main & Total & 44 & 20 & $0.455(+15.27 \%)$ & 0.395 & $0.564(+42.88 \%)$ & 0.27 \\
\hline & Main & Other & 61 & 40 & $0.656(+7.65 \%)$ & 0.609 & $0.769(+26.19 \%)$ & 0.32 \\
\hline & Outlier & Total & 106 & 58 & $0.547(+0.82 \%)$ & 0.543 & $0.663(+22.2 \%)$ & 0.47 \\
\hline & Outlier & Other & 38 & 42 & $1.105(+22.13 \%)$ & 0.905 & $1.190(+31.53 \%)$ & 0.26 \\
\hline \multirow[t]{9}{*}{ Rural } & All & All & 489 & 59 & $0.121(-5.7 \%)$ & 0.128 & $0.151(+17.68 \%)$ & 0.64 \\
\hline & Main & All & 220 & 31 & $0.141(-6.94 \%)$ & 0.152 & $0.192(+26.72 \%)$ & 0.77 \\
\hline & Outlier & All & 269 & 28 & $0.104(-8.83 \%)$ & 0.114 & $0.144(+26.24 \%)$ & 0.71 \\
\hline & All & Total & 204 & 27 & $0.132(-3.54 \%)$ & 0.137 & $0.173(+26.42 \%)$ & 0.55 \\
\hline & All & Other & 285 & 32 & $0.112(-9.76 \%)$ & 0.124 & $0.158(+27.3 \%)$ & 0.79 \\
\hline & Main & Total & 58 & 9 & $0.155(+6.29 \%)$ & 0.146 & $0.234(+60.46 \%)$ & 0.41 \\
\hline & Main & Other & 162 & 22 & $0.136(-9.33 \%)$ & 0.150 & $0.199(+32.67 \%)$ & 0.72 \\
\hline & Outlier & Total & 146 & 18 & $0.123(-6.38 \%)$ & 0.131 & $0.179(+36.24 \%)$ & 0.62 \\
\hline & Outlier & Other & 123 & 10 & $0.081(-12.37 \%)$ & 0.092 & $0.134(+44.96 \%)$ & 0.69 \\
\hline
\end{tabular}

$N$ setts is the total number of setts where problems occurred; $N$ problems is the total number of neighbouring problems that occurred in the period following management action; Ko and median Ke are the observed and expected frequencies of new problems, respectively (see "Methods" section for calculation); and the upper one-tailed $95 \%$ confidence limit above median $\mathrm{Ke}$ is presented. The percentage deviations from median Ke are presented in parentheses for the respective values of Ko and the upper confidence limits. $P$ is the approximate one-tailed $P$ value for differences between Ko and median Ke

and temporal scales of individual cases. Different cases were considered to refer to the same sett if (a) the distance separating them was $0 \mathrm{~m}$ (given the precision of the grid reference, this meant that they occupied the same $100 \times$ $100 \mathrm{~m}$ area), (b) they had the same site address, and (3) they were the same type of sett. Confidence intervals around the median Ke value reflected percentiles within the distribution of Ke statistics, while $P$ values for hypothesis tests were approximated based on the number of ranked $\mathrm{Ke}$ statistics that were higher or lower than Ko. One-tailed $P$ values and confidence limits $(<95$ th percentile) were calculated to test whether the frequency of neighbouring cases was greater than expected, while two-tailed $P$ values and confidence limits (2.5-97.5th percentiles) were used to test whether the frequency of reoccurrences was different (higher or lower) from expected. The significance of multiple hypothesis tests was controlled using the False Discovery Rate (Benjamini and Hochberg 1995), such that the expected proportion of type I errors among significant results was maintained at 0.05 . All analyses were carried out in R (version 2.6; R core development team 2007) using code written by the authors (Online Resource 1 in the Electronic Supplementary Material).
Spatial and temporal scale

Investigating the frequency of reoccurrences and neighbouring cases in relation to management action required an understanding of the appropriate temporal and spatial scales within which to assess associations between cases. We estimated that 1 year was a suitable time period during which new problems might elicit a licence application, since the majority of problems were reported by licensees to have started in the year prior to their licence application (J Davison \& R Delahay, unpublished data). We based our estimate of spatial scale on the average sizes of badger social group ranges, since these are likely to encompass the majority of typical movements and to contain alternative setts used by excluded or disturbed animals (Defra 2007). Any effects occurring within the ranges of affected badger groups could therefore be realistically attributed to the resident badgers. The mean size of rural badger group ranges across England is approximately 50 ha (Johnson et al. 2002), while in high-density urban and rural populations in southern England, where most sett-related problems arise, the figure is lower, at approximately 30 ha (Cresswell and 
Harris 1988; Rogers et al. 1997; Macdonald and Newman 2002; Davison et al. 2009). Thus, an area of 50 ha represents a conservative estimate of range size in badger populations where problems might arise. If a range of 50 ha is envisaged as a circle, its diameter (i.e. the greatest distance between setts within the same range and the average distance between the centre of each circular range) corresponds to approximately $800 \mathrm{~m}$. Therefore, analyses were primarily carried out using spatial and temporal scales of $800 \mathrm{~m}$ and 1 year, respectively. However, to exclude the possibility of overlooking important effects due to an inappropriate choice of spatial scale, we also calculated $\mathrm{Ko}$ and $\mathrm{Ke}$ for neighbouring cases at all scales between $200 \mathrm{~m}$ and 4,000 m, at 200-m increments with the temporal scale fixed at 1 year.

\section{Simulated problems}

To investigate the power of our technique to detect correlation between problem cases, we artificially generated additional urban cases within the chosen spatial $(800 \mathrm{~m})$ and temporal (licence expiry plus 1 year) scales of randomly selected existing cases. Urban cases were chosen since they represented the category of cases theoretically most likely to exhibit spatiotemporal correlation (see "Introduction" section). Simulated cases were incorporated into the full dataset after being allocated characteristics (including sett type and management action) randomly selected from existing cases in the data set ( $\mathrm{R}$ script for random data generation in Online Resource 1 in the Electronic Supplementary Material). The spatiotemporal analyses described above were then rerun on urban data sets that were artificially enlarged by $10,20,30$ or 40 cases.

\section{Results}

\section{Sample sizes}

Between January 2002 and March 2005, licences were granted to permit 369 management interventions at 336 different urban setts and 753 interventions at 697 rural setts throughout England. While there were seasonal variations in the numbers of applications for licences, there was no clear trend in numbers (increasing or decreasing) during the study period (Fig. 1). In urban areas, no sett was the subject of more than two separate applications, while in rural areas, no sett was subject to more than three. Main setts constituted $32 \%$ and $34 \%$ of problem setts in urban and rural areas, respectively, and total closure was licensed in $58 \%$ of urban and $41 \%$ of rural cases.
Background frequencies of cases

Expected $K$ statistics (i.e. Ke, generated by permuting all cases in the dataset) were used to investigate background frequencies of cases occurring throughout the study period. The background frequency of reoccurrences at individual setts was not significantly different between urban and rural environments (Fig. 2a). By contrast, there was a significantly higher background frequency of neighbouring cases (i.e. within 1-800 $\mathrm{m}$ of focal setts) in urban compared with rural areas (Fig. 2b). Background frequencies of reoccurrences and neighbouring cases associated with main and outlier setts were not significantly different once the differences between urban and rural areas were accounted for (Fig. 2).

Reoccurrences of problems at individual setts following management action

Frequencies of reoccurrences at focal setts in the time period following management action varied between $\mathrm{Ko}=$ 0.037 (other interference at rural main setts) and $\mathrm{Ko}=0.132$ (other interference at urban outlier setts), depending upon the combination of land use, sett type and management approach (Table 1). Observed frequencies of reoccurrences (Ko) differed from the respective median expected frequencies $(\mathrm{Ke})$ between $-30 \%$ and $+42 \%$, depending on the combination of land use, sett type and management approach (Table 1); however, in no cases did the observed frequencies fall outside of the $95 \%$ confidence limits for $\mathrm{Ke}$ (with $P$ always $>0.25$; Table 1 ).

Frequency of neighbouring cases following management action

Frequencies of neighbouring cases (i.e. within $1-800 \mathrm{~m}$ of focal setts) occurring in the time period following management action varied between $\mathrm{Ko}=0.081$ (other interference at rural outliers) and $\mathrm{Ko}=1.105$ (other interference at urban outliers) depending upon the combination of land use, sett type and management approach (Table 2). Observed frequencies of neighbouring cases (Ko) differed from the respective median expected frequencies $(\mathrm{Ke})$ between $-12 \%$ and $+22 \%$, depending on the combination of land use, sett type and management approach (Table 2); however, in no cases did the observed frequencies fall outside of the $95 \%$ confidence limits for Ke (with $P$ always $>0.23$; Table 2).

The frequency of neighbouring cases (Ko) was also investigated at a range of spatial scales for all combinations of land use, sett type and management action. This revealed that Ko exceeded the $95 \%$ confidence limit for Ke for certain combinations of land use, sett type and management 
Fig. 1 Numbers of applications for licences to interfere with badger setts in urban and rural areas of England throughout the study period. Only data for complete months are presented

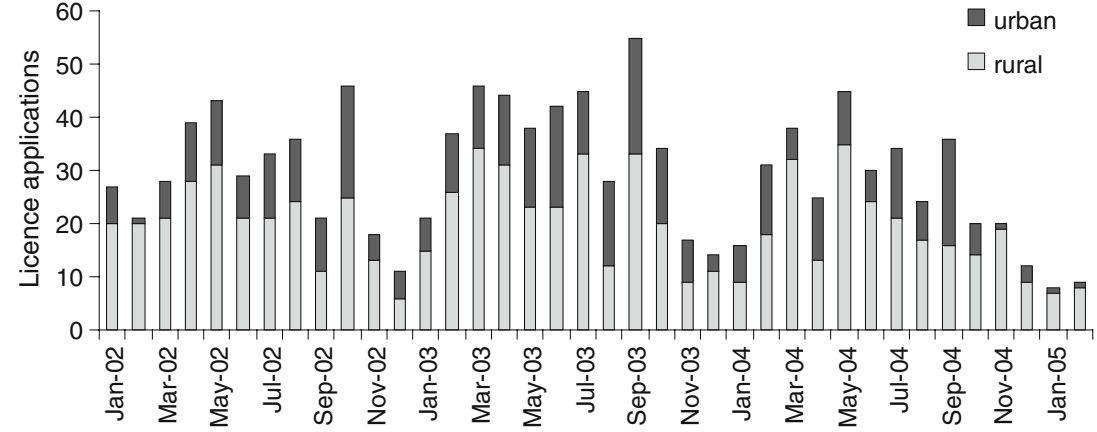

approach at certain spatial scales: $>1,200 \mathrm{~m}$ for other interference at urban main setts and outliers and $>3,000 \mathrm{~m}$ for other interference at rural outliers (Online Resource 2 in the Electronic Supplementary Material); however, the profiles of Ko in relation to spatial scale did not match our expectations about patterns arising from correlated
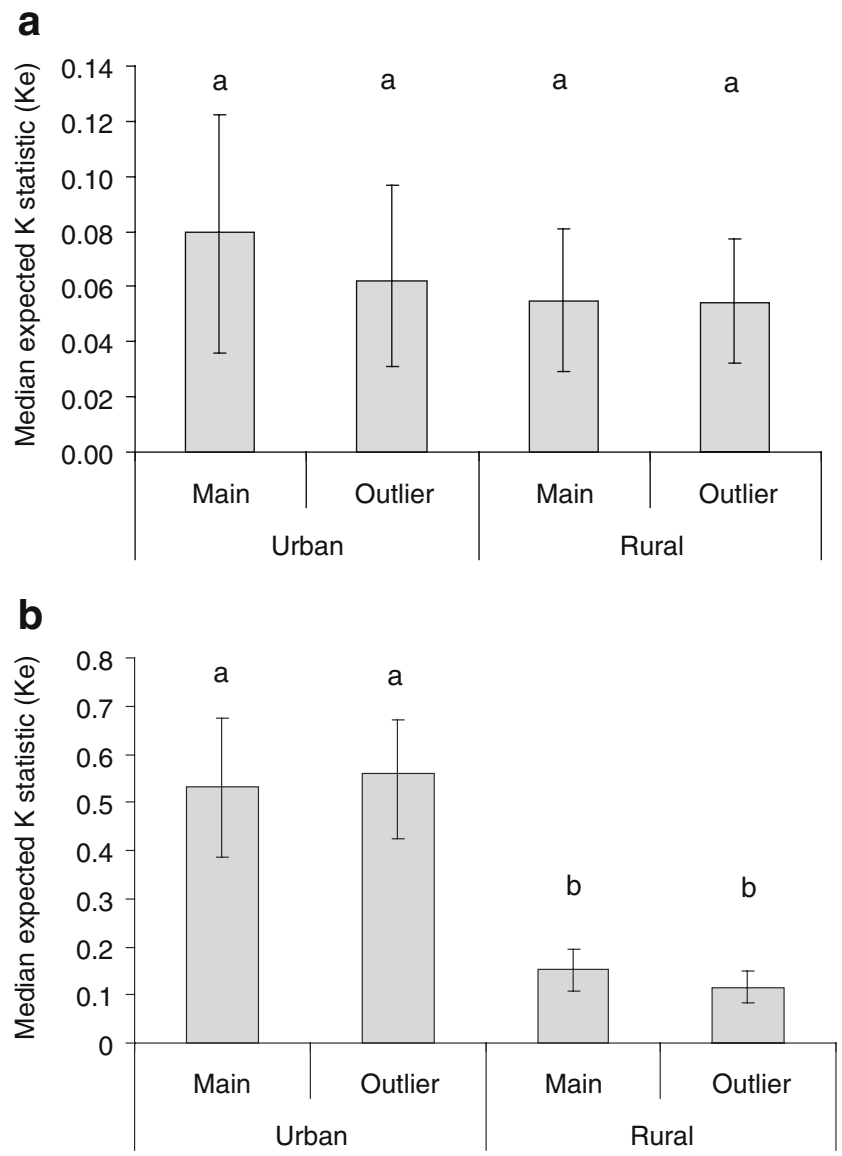

Fig. 2 Background frequencies of problems (median expected $K$ statistic) occurring in relation to different land use (urban or rural) and sett types (main or outlier): a reoccurrences at focal setts and $\mathbf{b}$ problems occurring in areas neighbouring setts $(<800 \mathrm{~m})$. Error bars show $95 \%$ confidence intervals, and different letters indicate significant differences $(P<0.05)$ between categories, based on pairwise comparisons of differences between permuted data subsets and a false discovery rate control of 0.05 cases (a unimodal peak at close distances, most likely in relation to urban main sett closure; see "Discussion" section for further interpretation).

While there was no significant spatiotemporal correlation between urban cases at a spatial scale of 1-800 m in the original data set (raw $P=0.25$; Table 2), the addition of 20 simulated problem cases (i.e. the equivalent of approximately $5 \%$ of the urban data set) led to significant correlation $(P<0.05)$, and this trend continued with the addition of further simulated cases $(P<0.01$ for 30 and 40 extra cases; Online Resource 3 in the Electronic Supplementary Material).

\section{Discussion}

The resolution of human-badger conflicts arising from damage to property is a complex and challenging problem in the UK. The database used in our analyses included estimates of both the costs sustained by licensees as a result of badger damage and the predicted expense had problems not been addressed. For sett-related problems in England occurring between January 2002 and March 2005, the estimated costs of existing damage reached just over $£ 1$ million, or approximately $£ 1,000$ per case, while the potential costs if problems were left untreated were considerably higher, at $£ 67$ million in total or $£ 60,000$ per case. The cost of excluding badgers and installing proofing to prevent future damage is also costly. We estimate that it costs about $£ 1,500-3,000$ to exclude badgers from a modest sized sett (four to six holes), but the costs of proofing and remedial work can greatly increase overall costs for exclusion operations. For domestic premises, total costs of $£ 5,000-£ 10,000$ are likely if the sett needs to be excavated and underground proofing installed. Reported costs for excluding badgers and repairing subsidence to roads are even higher, ranging from $£ 10,000$ to $£ 600,000$. Although damage figures can only be considered as crude approximations, they nonetheless provide an indication of the financial implications of problems related to badger setts. Although the need to protect human activities from these 
and other wildlife-related problems requires effective management strategies, there is relatively little objective evidence on the effectiveness and humaneness of interventions on which to base policy and advice to the public (Sillero-Zubiri et al. 2007).

While a preliminary field study indicated that badgers excluded from problem setts tended to make use of alternative resting locations within their existing range (Defra 2007), it is unclear whether such behaviour is likely to elicit new problems. It has been shown that urban raccoons excluded from breeding dens usually make new dens in nearby man-made structures (O'Donnell and DeNicola 2006). Similarly, carnivores translocated from an area where they have been responsible for livestock predation or other damage problems frequently return to the original area or exhibit similar nuisance behaviour elsewhere (Linnell et al. 1997; Bradley et al. 2005). Hence, it is important to gather objective evidence on the effectiveness of management strategies in order to avoid potentially damaging and costly outcomes.

Our results showed a similar background frequency of problems at individual urban and rural setts (i.e. Ke for 'reoccurrences'). This is notable since recent examples of recurrent problems at specific urban setts have received considerable public attention (e.g. Defra 2005). By contrast, the background frequency of problems in areas surrounding focal setts (i.e. Ke for 'neighbouring cases') was significantly higher in urban than in rural areas. A recent study showed that in England as a whole, the frequency of settrelated problems was higher in urban than in rural areas (Delahay et al. 2009), and the present analysis suggests that this phenomenon is likely to result from a larger number of setts per unit area causing problems in urban areas, rather than from a higher number of recurrent problems at individual setts. Furthermore, since sett densities in urban areas of England are not generally higher than those in corresponding rural areas (Harris 1984; Davison 2007; Davison et al. 2008), we can conclude that a higher proportion of setts in urban areas are likely to cause problems that are sufficiently serious to warrant a licence application. This is perhaps unsurprising given the higher density of humans and man-made structures in urban areas and the propensity for urban badgers to locate their setts in or close to gardens (Davison et al. 2009) and under manmade structures such as sheds, patios and roads (authors, personal observations).

The frequency with which problems reoccurred at focal setts following management action (i.e. Ko for 'reoccurrences') was not significantly different from the background frequency of problems occurring throughout the study period for any combination of land use, sett type or management action. Thus, no form of management action appeared to significantly increase the frequency of reoccur- rences, as might have been expected if management was generally unsuccessful. On the other hand, nor did it reduce the frequency of reoccurrences, as might have been expected in cases of total sett closure. Hence, these results suggest that the management actions currently available neither stimulate nor prevent the occurrence of further problems at the same site. The number of reoccurrences in the dataset was low: on average, a new problem at the focal sett in the year following management action only occurred following 1:20 rural and 1:12.5 urban cases (see Ko figures in Table 2). While this limited our power to detect significant differences between Ko and Ke (the confidence intervals in Table 2 represent increases of $<136 \%$ and decreases of $<100 \%$, relative to the median Ke values), it is in itself indicative that reoccurrences did not constitute a particularly frequent problem.

The Ko statistics in Table 2 indicate that new problems in locations close to focal setts (i.e. 'neighbouring cases' within $800 \mathrm{~m}$ ) arose more frequently following management action in urban (on average $0.46-1.10$ new problems per case) than rural (on average $0.08-0.16$ new problems per case) areas, broadly reflecting the pattern in the background frequency of cases. Indeed, we found no significant differences between observed and expected frequencies of neighbouring cases following any management action at any type of sett in either urban or rural areas. However, in contrast to the analysis of reoccurrences, the confidence limits above Ke for neighbouring cases suggested that a relatively powerful assessment of deviations from expected values was possible (the confidence intervals in Table 2 represent increases relative to median Ke values of $13 \%$ in urban and $18 \%$ in rural cases). Moreover, simulation of additional cases within the critical spatial and temporal scales of randomly selected real cases showed that our statistic was capable of detecting correlation between a relatively small number of cases. The addition of 20 correlated urban cases to the dataset spanning at least 3 years of real records (369 real records) caused a significant effect to become apparent in the analysis (Online Resource 3 in the Electronic Supplementary Material).

It is perhaps surprising that no differences were found when management resulted in total closure of urban main setts, since if badgers are deprived of access to a sett, they must presumably set up home elsewhere, and opportunities for digging or enlarging unproblematic setts may be more limited in urban compared with rural areas. Nonetheless, while the total closure of urban main setts may not always be successful in resolving acute damage problems (Delahay et al. 2009), there is no evidence from the present study to suggest that it results in displacing problems to areas within the chosen scale of $800 \mathrm{~m}$. Neither was there compelling evidence of association between cases at any other spatial scale between 200 and $4,000 \mathrm{~m}$. While the frequency of 
neighbouring cases exceeded expected values at spatial scales of $>1,200 \mathrm{~m}$ for other interference at urban setts and $>3,000 \mathrm{~m}$ for other interference at rural outliers, we consider it unlikely that these observations reflect association between problem cases for several reasons. First, the observations do not match our a priori predictions that new problems would be most likely to occur following total closure of urban main setts. It is not easy to explain why other interference should elicit more new problems than total closure. Second, while badger range size varies in relation to environmental and demographic variables, data from British badger populations suggest that the recorded excesses of cases occurred at scales that reflect the diameter of two to three typical badger group ranges. We anticipated that if new cases occurred as a consequence of management action, they would arise within the home ranges of affected groups. This view is supported by preliminary radio tracking evidence (DEFRA 2007) and matches the observation that badger groups typically have access to multiple small setts within their ranges (Kruuk 1978; Davison et al. 2008). Moreover, the pattern of territoriality exhibited by many badger populations means that excluded badgers might face opposition if they attempt to relocate to a neighbouring territory. Finally, the spatial profile of increases in new cases relative to expected values (i.e. the profile of the lines in Online Resource 2 in the Electronic Supplementary Material) did not reveal unimodal peaks at close distances, as might be expected, and which were generally evident in the simulated data (Online Resource 3 in the Electronic Supplementary Material). Rather, increases occurred at greater distances than we predicted and were sustained up to scales of $4,000 \mathrm{~m}$. Thus, it is perhaps most likely that the few observed excesses of cases represented a statistical artefact, especially in light of the number of comparisons performed when assessing multiple scales. Alternatively, spatiotemporal analyses can be affected by the influence of confounding factors (for a discussion in an epidemiological context, see Wakefield et al. 2000). An apparent excess of new problem cases following management action at badger setts could reflect spatial and temporal heterogeneity in phenomena related to badger or human populations. For example, there may be a degree of spatiotemporal autocorrelation in badger abundance, human population density and the extent to which the public is aware of the licensing process (i.e. local awareness might increase in response to an initial licensed case).

The results of this analysis must be treated with a degree of caution, since they relied on historical records that were collected for other purposes and hence risked overlooking unrecorded details of the process and problems that did not elicit a licence. Moreover, this analysis does not provide information about the success of licensed action (though see Delahay et al. 2009) or the welfare consequences of licensed action for badgers. Only detailed field studies are likely to be able to shed light on these questions. Nonetheless, our results suggest that, contrary to some claims, problems related to badger setts in urban areas do not appear to be more intractable than comparable rural problems. Rather, the higher frequency of problems arising in urban areas appears to be related to a higher probability that any sett in an urban area will become the source of a problem that requires licensed management. Moreover, it appears that the current approach for dealing with problem badger setts, and total sett closures in particular, are generally not implicated in the subsequent occurrence of new cases, either at focal setts or in neighbouring areas. This is an important finding as it provides confidence in a management strategy for conflict resolution that is adopted throughout the UK to deal with badger problems and in England alone is employed in 390-500 badger damage cases each year (Delahay et al. 2009; Natural England 2009).

Acknowledgements We wish to thank Dylan Poole and Ashley Matthews for their roles in the initial provision and processing of data on licensed operations and Paul Butt, Rodney Calvert, Claire Dowding, Mary Hunter, David Trump and two anonymous consultants for sett-exclusion cost estimates. This work was supported by Defra WSC under contract WM0304, the Estonian Ministry of Education and Sciences (target financing grant TLOOM0122), the Estonian Science Foundation (grant number GLOOM0058J) and the European Union through the European Regional Development Fund (Centre of Excellence FIBIR).

Ethical standards The management actions that provided the data used in this study were carried out in compliance with the laws of the United Kingdom.

Conflict of interest The authors declare that they have no conflict of interest.

\section{References}

Adams CE, Lindsey KJ, Ash SJ (2005) Urban wildlife management. CRC Press, Boca Raton

Benjamini Y, Hochberg Y (1995) Controlling the false discovery rate: a practical and powerful approach to multiple testing. J R Stat Soc B 57:289-300

Bradley EH, Pletscher DH, Bangs EE, Kunkel KE, Smith DW, Mack CM, Meir TJ, Fontaine JA, Niemeyer CC, Jiminez MD (2005) Evaluating wolf translocation as a non-lethal method to reduce livestock conflicts in the northwestern United States. Conserv Biol 83:279-289. doi:10.1111/j.1523-1739.2005.00102.x

Conover M (2002) Resolving human-wildlife conflicts: the science of wildlife damage management. CRC Press, Boca Raton

Cresswell WJ, Harris S (1988) Foraging behavior and home range utilization in a suburban badger (Meles meles) population. Mammal Rev 18:37-49

Davison J (2007) The ecology and behaviour of urban badgers Meles meles. DPhil Thesis, School of Life Sciences, University of Sussex, UK 
Davison J, Huck M, Delahay RJ, Roper TJ (2008) Urban badger setts: characteristics, patterns of use and management implications. J Zool 275:190-200. doi:10.1111/j.1469-7998.2008.00424.x

Davison J, Huck M, Delahay RJ, Roper TJ (2009) Restricted ranging behaviour in a high-density population of urban badgers. J Zool 277:45-53. doi:10.1111/j.1469-7998.2008.00509.x

Defra (2005) Monitoring the behaviour of individual badgers during a sett exclusion exercise: a report by the Central Science Laboratory and the Rural Development Service. Defra, UK

Defra (2007) Final report: development of a strategy for resolving urban badger damage problems-WM0304. http://randd.defra. gov.uk/

Delahay RJ, Davison J, Poole DW, Matthews AJ, Wilson CJ, Heydon MJ, Roper TJ (2009) Managing conflict between humans and wildlife: trends in licensed operations to resolve problems with badgers Meles meles in England. Mammal Rev 39:53-66. doi:10.1111/j.1365-2907.2008.00135.x

Diggle PJ (1983) Statistical analysis of spatial point pattern. Academic, New York

Diggle P, Chetwynd A, Haggkvist R, Morris S (1995) Second-order analysis of space-time clustering. Stat Meth Med Res 4:124-136

Donnelly CA, Woodroffe R, Cox DR, Bourne J, Cheeseman CL, Clifton-Hadely RS, Wei G, Gettinby G, Gilks P, Jenkins H, Johnston WT, Le Fevre AM, McInerney JP, Morrison WI (2006) Positive and negative effects of widespread badger culling on tuberculosis in cattle. Nature 439:843-846. doi:10.1038/nature 04454

Fortin M-J, Dale MRT (2005) Spatial analysis: a guide for ecologists. Cambridge University Press, Cambridge

Fortin M-J, Jacquez GM, Shipley B (2002) Computer-intensive methods. In: El-Shaarawi AH, Piegorsch WW (eds) Encyclopedia of environmetrics. Wiley, New York, pp 339-402

Haase P (1995) Spatial pattern analysis in ecology based on Ripley's K-function: introduction and methods of edge correction. J Veg Sci 6:575-582

Harris S (1984) Ecology of urban badgers Meles meles-distribution in Britain and habitat selection, persecution, food and damage in the city of Bristol. Biol Conserv 28:349-375

Harris S, Jefferies D, Cheeseman C, Booty C (1994) Problems with badgers? 3rd edn. RSPCA, Horsham

Johnson DDP, Jetz W, Macdonald DW (2002) Environmental correlates of badger social spacing across Europe. J Biogeogr 29:411-425
Knox G (1964) The detection of space-time interactions. J R Stat Soc C-Appl 13:25-29

Kruuk H (1978) Spatial organization and territorial behavior of the European badger Meles meles. J Zool 184:1-19

Linnell JDC, Aanes R, Swenson JE, Odden J, Smith ME (1997) Translocation as a method for managing problem animals: a review. Biodivers Conserv 6:1245-1257

Macdonald DW, Newman C (2002) Population dynamics of badgers (Meles meles) in Oxfordshire, UK: numbers, density and cohort life histories, and a possible role of climate change in population growth. J Zool 256:121-138. doi:10.1017/S0952836902000158

Matthews AJ, Wilson CJ (2005) The management of problems involving badgers (Meles meles). Protection of Badgers Act 1992 licensing cases 1997-1999. Defra, UK

Natural England (2009) Protection of badgers act 1992-licensing statistics. Natural England, Sheffield

O'Donnell MA, DeNicola AJ (2006) Den site selection of lactating female raccoons following removal and exclusion from suburban residences. Wildlife Soc B 34:366-370

Rogers LM, Cheeseman CL, Mallinson PJ, Clifton-Hadley R (1997) The demography of a high-density badger (Meles meles) population in the west of England. J Zool 242:705-728

Sillero-Zubiri C, Sukumar R, Treves A (2007) Living with wildlife: the roots of conflict and the solutions. In: Macdonald DW, Service K (eds) Key topics in conservation biology. Blackwell Publishing, Oxford

Thornton PS (1988) Density and distribution of badgers in south-west England: a predictive model. Mammal Rev 18:11-23

Wakefield JC, Kelsall JE, Morris SE (2000) Clustering, cluster detection, and spatial variation in risk. In: Elliott $P$, Wakefield JC, Best NG, Briggs DJ (eds) Spatial epidemiology: methods and applications. Oxford University Press, Oxford

Woodroffe R, Donnelly CA, Jenkins HE, Johnston WT, Cox DR, Bourne FJ, Cheeseman CL, Delahay RJ, Clifton-Hadley RS, Gettinby G, Gilks P, Hewinson RG, McInerney JP, Morrison WI (2006) Culling and cattle controls influence tuberculosis risk for badgers. Proc Natl Acad Sci USA 103:14713-14717. doi:10.1073/pnas.0606251103

Wilson CJ, Symes RG (1997) The management of problems involving badgers (Meles meles). Protection of Badgers Act 1992 licensing cases dealt with on behalf of the Ministry of Agriculture, Fisheries and Food in England from 1992 to 1996. Ministry of Agriculture Fisheries and Food, UK 